\title{
Platinum salt sensitivity in refinery workers: incidence and effects of smoking and exposure
}

\author{
A E Calverley, D Rees, R J Dowdeswell, P J Linnett, D Kielkowski
}

\begin{abstract}
Objective-To measure the incidence of platinum salt sensitivity (PSS) in refinery workers and examine the influence of cigarette smoking and exposure to platinum salts on sensitisation.

Design-A prospective cohort study with examination of workers at quarterly intervals for 18 months, and again at 24 months.

Setting-A South African primary platinum refinery.

Subjects-78 new recruits, selected by the refinery's usual procedure, without apparent atopy and in good respiratory health.

Results-After 24 months 32 (41\%) subjects had been diagnosed PSS and were subsequently medically separated. Twenty two $(28 \%)$ cases were confirmed by positive skin prick test to platinum salts, 10 (13\%) cases were symptomatic but skin prick negative. Incidence of cases per 100 person-months was 1.9 skin prick positive and 0.8 negative. Risk of sensitisation was about eight times greater for smokers than non-smokers, and six times greater for high exposure than low exposure.

Conclusion-Smoking and intensity of exposure were definitely associated with development of PSS. Positive response to platinum salt skin prick test had a $100 \%$ positive predictive value for symptoms and signs of PSS if exposure continued.
\end{abstract}

(Occup Environ Med 1995;52:661-666)

Keywords: platinum salt sensitivity; occupational allergy; occupational asthma

Platinum salt sensitivity (PSS) is well documented and sensitised people may present with asthma, rhinitis, urticaria, and dermatitis. ${ }^{1-3}$

Many studies of PSS have been reported, cross sectional surveys, ${ }^{4-6}$ cohort studies s.9 $^{7-9}$ and a historical prospective cohort study. ${ }^{10}$ Their usefulness is limited as cross sectional surveys tended to study a "survivor" population whereas other studies started at a particular event (usually medical separation) and data before exposure and data on unaffected workers were often unavailable. The effects of smoking and exposure intensity have each been explored but a comprehensive study of both influences together has not been reported.
A prospective study design starting at employment was indicated ${ }^{11}$ to avoid the limitations described. This study, which examined new recruits to a platinum refinery before employment and at intervals during their period of work exposure, was formulated to meet the following objectives.

(1) To determine the incidence of PSS in recruits who satisfied entry criteria for employment.

(2) To investigate the role of tobacco smoking in the development of PSS.

(3) To examine the effect of level of exposure on sensitisation to soluble platinum salts.

\section{Methods}

The study population initially numbered 90 , and included all new recruits accepted for permanent or long term employment within the vicinity of the refining process, between January 1986 and June 1987. The usual recruitment procedure of the refinery was used, including a medical examination. A history of chronic respiratory disease, allergy symptoms, lung function below prescribed limits, or a positive response to skin prick test with either platinum salts or common allergens precluded employment. Exclusion of recruits with a positive skin prick test to common allergens has become a practice since it was suggested that atopy could increase the risk of sensitisation to platinum salts. ${ }^{12}$

Written informed consent was obtained from all 90 recruits and they were entered into the study at the start of employment. Participants were subsequently reduced by 12 who left the study before the first examination after the start of employment. The final number of 78 subjects studied consisted of 61 white (60 men, one woman), and 17 black men, 44 subjects were employed in production as process controllers and the remaining 34 were in ancillary services, security, cleaning, maintenance, laboratory, and canteen. No administrative or office staff were included.

During the same period an additional 152 temporary, contract, and office staff were employed but not included in the study. Of these, 28 were office workers, 28 worked for less than three months, for 41 there was no record of exact time worked, and three had possible previous exposure to platinum salts. Records of time worked and ending of employment because of PSS confirmed by positive skin prick test to platinum salt were available for 52 of these 152 workers.

The study design was a prospective cohort

PO Box 4788,

Johannesburg

Accepted 19 June 1995 
study that examined workers before exposure and at three month intervals thereafter for a period of 18 months, or until they left the refinery, whichever occurred first. A final examination after 24 months was conducted on all subjects still employed.

Data collected at clinical examinations consisted of:

(1) Completion of questionnaire detailing: (a) before exposure-smoking history specified by cigarettes smoked a day, health history, previous work exposure to platinum salts and other potentially hazardous materials, current health particularly of respiratory, skin, and eye symptoms; (b) during exposure-current cigarettes smoked a day, job and sections worked during previous three months; respiratory symptoms (cough, shortness of breath, wheeze), asthma, rhinitis, eye and skin symptoms; onset, severity, and duration of symptoms, any improvement away from the workplace, and whether subject perceived symptoms to be work related.

(2) Lung function tests before and after inhaled $\beta_{2}$ agonist. Bronchospasm was defined as a reduction in $\mathrm{FEV}_{1}$ of more than $15 \%$ compared with before exposure, reversible with time or a bronchodilator.

(3) Skin prick tests with platinum salts and common allergens. These were carried out by the standard method, a superficial prick through drops of allergens placed on the volar surface of the forearm. A weal and flare with induration of more than $2 \mathrm{~mm}$ was considered positive. Platinum salts $\left(10^{-3} \mathrm{~g} / \mathrm{ml}\right)$ used were sodium hexachloroplatinate, sodium tetrachloroplatinite, and ammonium hexachloroplatinate. Common allergens used were house dust, house dust mite, grass pollen, and Bermuda grass mix supplied by Bayer Miles. Negative controls were used to exclude nonspecific reactions.

At three month intervals clinical examinations were carried out by the refinery medical officer, who had access to completed questionnaires and skin prick test results. As well as monitoring symptoms and signs of PSS for the purposes of the study, he was also responsible for the subjects' occupational health care. Results of clinical examinations are not presented.

A diagnosis of PSS was made if the subject had a positive response to skin prick test with platinum salts or symptoms and signs consistent with PSS that, in the opinion of the attending medical officer, were so severe that employment should end on medical grounds. These symptoms and signs included immediate or delayed bronchospasm, rhinitis, eye symptoms, urticaria, or dermatitis in response to exposure to platinum salts.

Subjects were categorised by diagnosis as: (a) PSS sensitive-positive to skin prick test to platinum salts, which confirms sensitisation, (b) PSS symptomatic-diagnosed and employment ended on medical grounds because of symptoms and signs, but negative response to skin prick test with platinum salts, (c) PSS negative-negative response to skin prick test with platinum salts and without symptoms and signs consistent with PSS.

The workplace of the subjects studied was a refinery engaged in the primary refining of platinum group metals. Air concentrations of platinum salts were monitored and recommended occupational hygiene control guidelines were followed, ${ }^{12}$ the use of respiratory protection for high risk areas and tasks was enforced. This was an airstream helmet with a high efficiency filter, or a full face mask with double filters, or a sealed mask unit supplied with compressed air, as appropriate.

Conditions at the refinery were such that it was probable that all subjects were exposed to platinum salts to some degree, as has been reported in other platinum refineries..$^{5}$ Thus intensity of exposure was categorised as a dichotomous grading of either low or high in each work section of the refinery. Initially refinery management was asked to grade the intensity of exposure in each section from their experience of the refining process. These subjective assessments were validated from the records of the company's environmental monitoring. As this had been done for the information of refinery management in the pursuance of a sound occupational hygiene programme, more samples were taken in high risk sections, and particularly when problems had occurred, to assess and deal with such occurrences. Table 1 shows the percentages of measurements of platinum salts in air from all personal samples taken in 24 work sections for a representative period in 1986 that exceeded the recommended maximum or threshold limit value (TLV) of $2 \mu \mathrm{g} / \mathrm{m}^{3}$ when assayed by the method described by the British Health and Safety Executive. ${ }^{13}$ These are included to support the gradings of exposure intensity, they are not an assessment of actual inhaled dose, as measurements did not reflect the protection afforded by respiratory equipment, and bias was exerted by the monitoring strategy of sampling more often in high risk situations.

Subjects were graded as highly exposed if they worked in sections where, at times, the TLV was exceeded (although median air concentration was below the TLV). Maintenance personnel were classified as highly exposed, in view of frequent contact with refining process equipment, often in a breakdown situation when immediate maintenance or disassembly was required. All other non-production staff were classified as exposed at low intensity,

Table 1 Percentage of samples where air concentration of platinum salts exceeded the TLV $\left(2 \mu \mathrm{g} / \mathrm{m}^{3}\right)$, summarised by dichotomous categorisation of exposure and general area.

\begin{tabular}{llll}
\hline & $\begin{array}{l}\text { Sections } \\
(n)\end{array}$ & $\begin{array}{l}\text { Total } \\
(n)\end{array}$ & $\begin{array}{l}>T L V \\
(\%)\end{array}$ \\
\hline $\begin{array}{l}\text { High exposure } \\
\text { production areas }\end{array}$ & 17 & 566 & 27 \\
$\begin{array}{l}\text { Low exposure } \\
\text { non-production services } \dagger\end{array}$ & 7 & 45 & 0 \\
Total & 24 & 611 & 25 \\
\hline
\end{tabular}

^Production areas include maintenance and incinerator; tnonproduction services = security, canteen and cleaning, changehouses. 
Table 2 Characteristics of subjects by PSS category

\begin{tabular}{|c|c|c|c|c|}
\hline & $\begin{array}{l}\text { Total study } \\
\text { group }\end{array}$ & $\begin{array}{l}\text { PSS } \\
\text { sensitive }\end{array}$ & $\begin{array}{l}\text { PSS } \\
\text { symptomatic }\end{array}$ & $\begin{array}{l}\text { PSS } \\
\text { negative }\end{array}$ \\
\hline $\begin{array}{l}\text { Subjects (n) } \\
\text { Production staff } \\
\text { Non-production staff }\end{array}$ & $\begin{array}{l}78 \\
44(56) \\
34(44)\end{array}$ & $\begin{array}{l}22 \\
16(73)^{\star} \\
6(27)^{\star}\end{array}$ & $\begin{array}{l}10 \\
8(80)^{\star} \\
2(20)^{\star}\end{array}$ & $\begin{array}{l}46 \\
20(43) \\
26(57)\end{array}$ \\
\hline $\begin{array}{l}\text { Race: } \\
\text { Black } \\
\text { White }\end{array}$ & $\begin{array}{l}17(22) \\
61(78)\end{array}$ & $\begin{array}{r}6(27) \\
16(73)\end{array}$ & $\stackrel{0}{10}(100)$ & $\begin{array}{l}11(24) \\
35(76)\end{array}$ \\
\hline $\begin{array}{l}\text { Smoking: } \\
\text { Non-smoker } \\
\text { Smoker } \\
\text { 1-9 Cigarettes/day } \\
\text { ₹ 10 Cigarettes/day } \\
\text { Median Cigarettes/day }\end{array}$ & $\begin{array}{l}35(45) \\
43(55) \\
18(23) \\
25(32) \\
3\end{array}$ & $\begin{array}{l}4(18)^{\star} \\
18(82)^{\star} \\
8(36) \\
10(45) \\
5\end{array}$ & $\begin{array}{l}4(40) \\
6(60) \\
0 \\
6(60) \\
10\end{array}$ & $\begin{array}{r}27(59) \\
19(41) \\
8(17) \\
11(24) \\
0\end{array}$ \\
\hline $\begin{array}{l}\text { Exposure: } \\
\text { Months to outcome: } \\
\text { Group total } \\
\text { Median }\end{array}$ & $\begin{array}{r}1177 \\
14\end{array}$ & $\begin{array}{r}292 \\
12\end{array}$ & $\begin{array}{r}123 \\
12\end{array}$ & $\begin{array}{r}762 \\
22\end{array}$ \\
\hline $\begin{array}{l}\text { Graded exposure: } \\
\text { Low n (\%) } \\
\text { High n (\%) }\end{array}$ & $\begin{array}{l}34(44) \\
44(56)\end{array}$ & $\begin{array}{r}5(23)^{\star} \\
17(77)^{\star}\end{array}$ & ${ }_{10}^{0}(100)^{\star}$ & $\begin{array}{l}29(63) \\
17(37)\end{array}$ \\
\hline
\end{tabular}

$\star \mathrm{P}<0.05 v$ PSS negative. cation of results by race was not justified. Multivariate analyses were done with Cox's proportional hazards survival regression model, with the assistance of "EGRET" software. ${ }^{15}$ Smoking and exposure intensity were both measured as dichotomous variables, (smoker or non-smoker, low or high). Two models were used, one examined the risk of becoming PSS sensitive in which PSS symptomatic people were regarded as negative. The second model examined the risk of developing disease related to platinum salts where only PSS negative people were considered negative. Kaplan-Meier estimates of the probability of the workers remaining negative to skin prick with platinum salts, were done with the same software package. ${ }^{15}$

\section{Results}

Of the study population of 78 new recruits employed over a period of 18 months, 32 $(41 \%)$ were diagnosed as having disease related to platinum salts within two years of employment, and their employment was subsequently ended on medical grounds. Twenty two $(28 \%)$ developed a positive response to soluble platinum salts on skin prick test and were categorised as PSS sensitive, $10(13 \%)$ were unresponsive to skin prick test but were diagnosed on symptoms and signs as PSS symptomatic, the remaining 46 (59\%) were PSS negative.

Table 2 presents characteristics of the study group both as a whole and divided into PSS categories, table 3 presents the number and incidence of cases (or total months worked by PSS negative people) both in total and stratified by exposure intensity, by smoking habits of the workers. For clarity, results for PSS sensitive and PSS symptomatic workers are discussed separately, followed by multivariate analyses.

\section{PSS SENSITIVE}

An incidence of 1.9 PSS sensitive cases/100 person-months worked was found. Figure 1

Table 3 Smoking habits and incidence of cases by exposure characteristics in each PSS category

\begin{tabular}{|c|c|c|c|c|c|c|c|}
\hline & \multirow{2}{*}{$\begin{array}{l}\text { Non- } \\
\text { smokers }\end{array}$} & \multicolumn{6}{|c|}{ Smokers by median cigarettes/day } \\
\hline & & Smoker & $1-4$ & $5-9$ & $1-14$ & $15-19$ & $\geqslant 20$ \\
\hline Total (n) & 35 & 43 & 9 & 9 & 12 & 8 & 5 \\
\hline Low exposure (n) & 16 & 18 & 6 & 6 & 3 & 2 & 1 \\
\hline High exposure (n) & 19 & 25 & 3 & 3 & 9 & 6 & 4 \\
\hline \multicolumn{8}{|l|}{ PSS Sensitive: } \\
\hline Total (n (\%)) & $4(11)$ & $18(42)$ & $6(67)$ & $4(44)$ & $5(42)$ & $3(38)$ & 0 \\
\hline Incidence ${ }^{\star}$ & 0.7 & $3 \cdot 2$ & $3 \cdot 8$ & & 3.9 & 3 & - \\
\hline Low exposure (n (\%)) & 0 & $5(12)$ & $3(33)$ & $2(22)$ & - & - & - \\
\hline Incidence & & $1 \cdot 6$ & $2 \cdot 5$ & 1.9 & - & & - \\
\hline High exposure (n (\%)) & $4(11)$ & $13(30)$ & $3(33)$ & $2(22)$ & $5(42)$ & $3(38)$ & \\
\hline $\begin{array}{l}\text { Incidence } \\
\text { PSS Symptomatic. }\end{array}$ & $1 \cdot 3$ & $5 \cdot 2$ & $8 \cdot i$ & $6 \cdot 3$ & 6.0 & $5 \cdot 5$ & - \\
\hline \multicolumn{8}{|l|}{ PSS Symptomatic: } \\
\hline $\begin{array}{l}\text { Total (n (\%)) } \\
\text { Incidence }\end{array}$ & $\begin{array}{l}4(11) \\
0.7\end{array}$ & $\begin{array}{l}6(14) \\
1 \cdot 1\end{array}$ & $\underline{0}$ & $\underline{0}$ & $\begin{array}{l}1(8) \\
0 \cdot 8\end{array}$ & $\begin{array}{l}2(25) \\
2 \cdot 0\end{array}$ & $\begin{array}{l}3(60) \\
10 \cdot 0\end{array}$ \\
\hline Low exposure (n (\%)) & 0 & 0 & - & - & - & & \\
\hline High exposure (n (\%)) & $4(11)$ & $6(14)$ & - & - & $1(8)$ & $2(25)$ & $3(60)$ \\
\hline Incidence & $1 \cdot 3$ & $2 \cdot 4$ & - & - & $1 \cdot 2$ & 3.6 & $11 \cdot 1$ \\
\hline \multicolumn{8}{|l|}{ PSS Negative } \\
\hline Total $(\mathrm{n}(\%))$ & $27(7)$ & $19(44)$ & $3(33)$ & $5(56)$ & $6(50)$ & $3(38)$ & $2(40)$ \\
\hline Total months worked & 476 & 286 & 64 & 107 & 58 & 51 & 6 \\
\hline $\begin{array}{l}\text { Low exposure (n (\%)) } \\
\text { Total months worked }\end{array}$ & $16(46)$ & $\begin{array}{l}13(30) \\
238\end{array}$ & $\begin{array}{l}3(33) \\
64\end{array}$ & $\begin{array}{l}4(44) \\
83\end{array}$ & $\begin{array}{l}3(25) \\
43\end{array}$ & $\begin{array}{l}2(25) \\
45\end{array}$ & $\begin{array}{l}1 \\
3\end{array}$ \\
\hline $\begin{array}{l}\text { Total months worked } \\
\text { High exposure (n (\%)) }\end{array}$ & $11(31)$ & $6(14)$ & 0 & $\begin{array}{l}83 \\
1(11)\end{array}$ & $3(25)$ & $1(13)$ & $1(20)$ \\
\hline Total months worked & 182 & 48 & - & 24 & & 6 & 3 \\
\hline
\end{tabular}

*Incidence calculated as cases/ 100 person months worked. 
Figure 1 Crude incidence of PSS sensitive and PSS symptomatic cases $/ 100$ person-months.

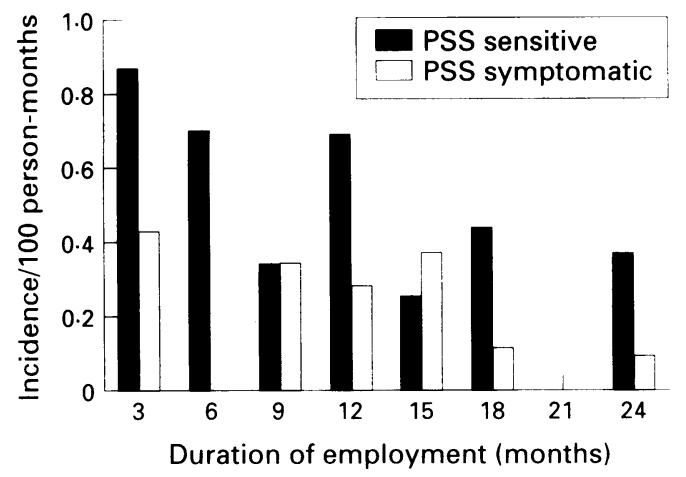

shows that crude incidence did not increase with increasing duration of exposure, cases occurred at a higher rate after three months than after 24 months of employment $(0.9 v$ 0.4 cases/100 person-months, respectively).

All 22 PSS sensitive subjects eventually developed symptoms and signs that led to the end of their employment on medical grounds. In 12 cases this occurred simultaneously with first positive skin prick reaction to platinum salts, and in the remaining 10 cases between one and 20 months (median 8.5 months) after first skin prick response. Thus, in this study, skin prick tests to platinum salts had a $100 \%$ positive predictive value for end of employment on medical grounds when exposure continued.

Table 2 shows that PSS sensitive workers were employed more frequently in production capacities $(73 \%)$ than PSS negative workers (43\%) $\mathrm{P}=0.025$, and thus more were graded as highly exposed $(77 \% v 37 \%, \mathrm{P}=0.002)$. Proportionally twice as many PSS sensitive workers smoked, than did the PSS negative workers $(82 \% v 41 \%, \mathrm{P}=0.002)$, but the fact that more were heavy smokers (45\% PSS sensitive $v 24 \%$ PSS negative) was not significant.

This apparent association with both smoking and exposure and PSS sensitive cases was confirmed when exposure data were stratified by smoking for the three PSS categories. Table 3 shows that among subjects at high exposure a significantly larger proportion, $30 \%$, of the PSS sensitive group were smokers, compared with $14 \%$ of the PSS negative group ( $\mathrm{P}=$ $0.017)$. In subjects exposed at low intensity all 16 non-smokers remained PSS negative, as did 13 of the smokers, only five were PSS sensitive ( $P=0.046)$. Incidence of cases $/ 100$ person-months worked (by subjects in specific smoking categories) indicated that in general non-smokers withstood exposure longer than smokers $(0.7 v 3.2$ cases/ 100 person-months). High exposure led to an incidence at least three times higher than low exposure across all

Table 4 The effects of smoking and exposure category on the risk of becoming PSS sensitive specifically, or PSS (sensitive or symptomatic)

\begin{tabular}{|c|c|c|c|}
\hline & $n$ & Hazard ratio $(95 \% \mathrm{CI})$ & Pvalue \\
\hline PSS sensitive: & 78 & & \\
\hline Smoking & & $8 \cdot 0(2 \cdot 6-25 \cdot 0)$ & $<0.001$ \\
\hline Exposure & & $6 \cdot 2(2 \cdot 2-17 \cdot 7)$ & $<0.001$ \\
\hline PSS (sensitive or symptomatic): & 78 & & \\
\hline Smoking & & $5 \cdot 3(2 \cdot 3-12 \cdot 6)$ & $<0.001$ \\
\hline Exposure & & $9 \cdot 0(3 \cdot 5-24 \cdot 3)$ & $<0.001$ \\
\hline
\end{tabular}

smoking categories $(5 \cdot 2 \quad v \quad 1.6$ cases $/ 100$ person-months among all smokers). Among smokers an increase in median number of cigarettes smoked a day did not increase the incidence of PSS sensitive cases.

The 52 workers not included in the study worked for a mean of 14 months, there were 11 PSS sensitive cases (that occurred at a median of eight months), a crude incidence of 1.5 cases/100 person-months. Nine of these affected workers were smokers with high exposure, one was a smoker with low exposure, and the 11 th a non-smoker with high exposure.

\section{PSS SYMPTOMATIC}

All 10 subjects in this group were released from work on medical grounds on a diagnosis of PSS. Symptoms and signs seemed to be work related and included asthma confirmed by lung function tests in seven cases, the three unconfirmed cases had all required medical attention for symptoms and signs of asthma. Crude incidence of PSS symptomatic cases was $0 \cdot 7 / 100$ person-months worked. A median of 12 months was worked before diagnosis and incidence of new cases at three month examinations declined over time (fig 1).

Comparison of smoking characteristics (table 2) shows that in the PSS symptomatic group the proportion of smokers $(60 \%)$ closely reflects that of the whole study population $(55 \%)$, but the proportion of heavy smokers $(60 \%)$ was higher than in any other group. Exposure characteristics (table 2) show that these PSS symptomatic subjects, compared with PSS negative subjects, were all graded as exposed to a high intensity of platinum salts $(100 \%$ v $37 \%, P=0.0002)$. Intensity of exposure thus was a major predictor of PSS symptomatic cases. Among smokers incidence was shown (table 3 ) to increase with median number of cigarettes smoked a day. The highest rate, 11.1 PSS symptomatic cases/100 personmonths, was recorded for subjects with high exposure who smoked 20 or more cigarettes a day, and accounted for three of only four such subjects included in the study population.

\section{MULTIVARIATE ANALYSIS}

The independent effects of smoking and exposure were measured by multivariate analysis. Table 4 shows that from the results presented (with confidence intervals (CIs)) the risk of becoming PSS sensitive was eight times greater in smokers than non-smokers (adjusted for exposure), and six times greater at high than low intensity of exposure (adjusted for smoking). For employment to end on medical grounds a diagnosis of either PSS sensitivity or symptoms exposure was more important, the risk being nine times greater at high than low exposure.

The Kaplan-Meier model (fig 2) graphically presents the probability of workers, in different smoking and exposure categories, surviving employment without becoming PSS sensitive, thus PSS symptomatic workers are regarded as negative. No non-smoking worker with low exposure developed a positive skin prick test to platinum salts within the two years (survival 
Figure 2 Probability of refinery workers remaining skin prick negative, by smoking and exposure categories.

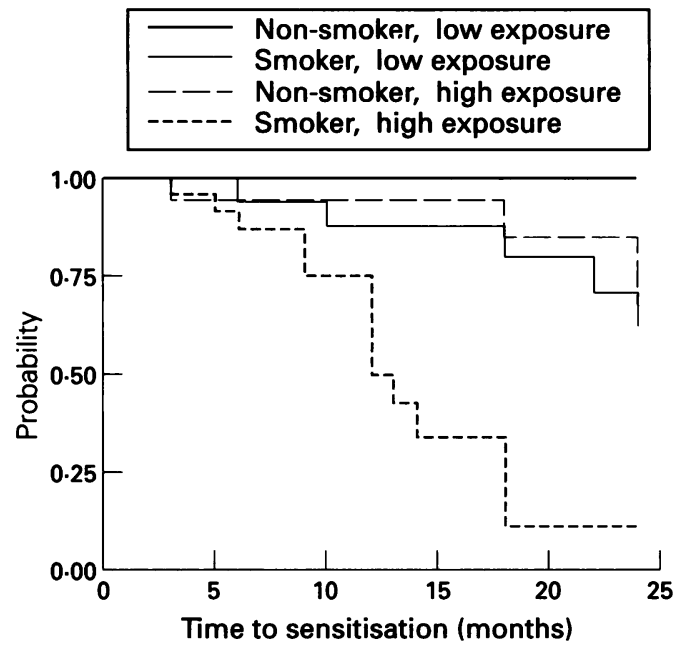

probability $=1.00$ or $100 \%$ ). In contrast, smokers with high exposure had the worst 24 month survival probability, only $0 \cdot 114$. In general smokers were diagnosed after shorter service than non-smokers; 16 of their 18 failures ( $89 \%$ ) had occurred by 18 months of employment, compared with only two of the four failures $(50 \%)$ of the non-smokers.

Avoidance of the end of employment on medical grounds due to disease related to platinum salts overall (PSS sensitivity or symptoms) is not illustrated, but probabilities for workers in the high exposure group declined to 0.445 (at 24 months) for nonsmokers and 0.052 (at 18 months) for smokers.

\section{Discussion}

The main objectives of the study were to investigate the incidence of sensitivity to platinum salts and the influence of smoking and exposure. Incidence of disease related to platinum salts (leading to subsequent medical ending of employment) within 24 months, was high, $2 \cdot 7$ cases $/ 100$ person-months, or $41 \%$ of apparently non-atopic, healthy recruits. Most of the 22 PSS sensitive cases, confirmed by positive skin prick test occurred within 12 months of employment. The study population seems to be representative of the workforce as a whole, incidence of PSS sensitive cases among workers not included was comparable $(1.5 v$ 1.9 cases/100 person-months). Our findings were similar to those in the only prospective study available for comparison, the historical cohort study of Venables et al, ${ }^{10}$ where incidence of sensitisation for the first 24 months was $3 \cdot 1$ cases $/ 100$ person-months for workers recruited in 1973-4. The lower incidence of sensitisation of 1.9 cases/100 person-months in our study was predictable, $44 \%$ of subjects were non-production staff, whereas the study population in the study of Venables et al were all production staff and included a higher percentage of smokers and some atopic subjects.

All PSS sensitive subjects developed symptoms and signs of allergic disease but this was subsequent to positive skin prick in most cases, the median interval being 8.5 months. Positive response to platinum salt skin prick test thus had a $100 \%$ positive predictive value for symptoms and signs of PSS (if exposure continued). Prompt, permanent removal from exposure at positive skin prick test may well avoid subsequent progression of the disease process. ${ }^{12}$ Bias in diagnosis resulting from previous knowledge of skin prick results was a possibility, but was probably minimised by the refinery medical officer's experience in cases of PSS.

Subjects who were PSS symptomatic were investigated as they made up almost a third of the workers lost to employment for medical reasons in this study. Other researchers have identified similar cases, ${ }^{12}$ but exact aetiology has not been established. This group probably comprises subjects reacting by more than one mechanism. Studies have identified subjects who develop symptoms and signs before a positive skin prick response ${ }^{1016}$; and symptomatic workers who reacted to platinum salts on bronchial provocation testing, despite nonresponse to skin prick tests. ${ }^{9}$ Some symptoms and signs may be related to other allergens and irritants used in the refining process, or to smoking (smokers in this group were all heavy smokers).

An association between disease related to platinum salts and smoking has been noted in other studies. Venables et al ${ }^{10}$ showed smoking to be the most important predictor of sensitisation with risk estimated as four to five times greater in smokers than in non-smokers. Our higher (eightfold) risk estimate in smokers may be explained by differences in the rate of staff turnover. Within 24 months the decline in the population in the study of Venables et al was $30 \%$ higher than in ours, and smokers were more likely to leave (as in our study), so relatively more potential candidates for sensitisation, particularly smokers, were lost to the other study. Consistent with findings of this study a dose-response effect between cigarettes smoked a day was not found in PSS sensitive cases, but was evident among PSS symptomatic subjects who smoked.

Smoking and increased intensity of exposure were shown to be independently strongly associated in PSS sensitive cases: we were unable to confirm an interaction between the factors (suggested in fig 2) with interactive terms (smoking $\times$ exposure) possibly due to the relatively small data set.

Reservations expressed about bias exerted by "survivor" populations on cross sectional surveys were confirmed by this study. Within 24 months the study population of 78 was reduced by the ending of employment on medical grounds and natural attrition to 23 . Non-smokers with low exposure accounted for $21 \%$ of entrants but $39 \%$ of the survivors, and smokers with high exposure were $32 \%$ of entrants but only $4 \%$ of the survivor group. Examination of the study by Venables et $a l^{10}$ indicates a similar pattern. If this occurs in other refineries it would contribute to the generally accepted understanding that most platinum salt sensitisation occurs within two years of employment; after this time most workers at greatest risk would have left the industry. 
Logical recommendations would be employment of non-smokers, and continued reduction in concentration of platinum salts in the air of work areas. These measures, combined with prompt removal from exposure of all workers with a positive skin prick test to platinum salts should considerably reduce the incidence of sensitivity to platinum salt in refinery personnel.

We thank the refinery management and staff for their participation in the study. We are especially grateful to the refinery medical centre staff for their co-operation and meticulous data collection.

1 Hunter D, Milton R, Perry KMA. Asthma caused by the complex salts of platinum. $\mathrm{Br} \mathcal{F}$ Ind Med 1945;2:92-8.

2 Roberts AE. Platinosis. A five year study of the effects of soluble platinum salts on employees in a platinum laboratory and refinery. Arch Ind Hyg Occup Med 1951;4: 549-55.

3 Pepys J. Occupational allergy due to platinum complex salts. Clin Immunol Allergy 1984;4:131-57.

4 Murdoch RD, Pepys J, Hughes EG. IgE antibody responses to platinum group metals: a large scale refinery responses to platinum group metals:

5 Baker DB, Gann PH, Brooks MD, Gallagher J, Bernstein II. Cross-sectional study of platinum salts sensitization IL. Cross-sectional study of platinum salts sensitization among precious
6 Merget R, Scultze-Werninghaus G, Muthorst T, Friedrich W, Meier-Sydow J. Asthma due to the complex salts of platinum - a cross-sectional survey of workers in a platinum refinery. Clin Allergy 1988;18:569-80.

7 Pepys J, Pickering CAC, Hughes EG. Asthma due to inhaled chemical agents-complex salts of platinum. Clin Allergy 1972;2:391-6.

8 Cremoll Pes Jugh Specific IgE antibodies to platinum salt in sensitised workers. Clin antibodies to platinum

9 Merget R, Schultze-Werninghaus G, Bode F, Bergmann Merget R, Schultze-Werninghaus G, Bode F, Bergmann
EM, Zachgo W. Quantitative skin prick and bronchial provocation tests with platinum salt. $B r \mathcal{F}$ Ind Med 1991 48:830-7.

10 Venables KM, Dally MB, Nunn AJ, Stevens JF, Stephens $R$, Farrer N. Smoking and occupational allergy in workers in a platinum refinery. BMF 1989;299:939-42.

11 Linnett PJ. Platinum salt sensitivity: a review of the health aspects of platinum refining in South Africa. Fournal of the Mine Medical Officers Association of South Africa 1987;63: 24-8.

12 Hughes EG. Medical surveillance of platinum refinery workers. F Soc Occup Med 1980;30:27-30.

13 Health and Safety Executive Occupational Medicine and Hygiene Laboratories. Platinum metal and soluble inorganic compounds of platinum in air. Methods for the determination of hazardous substances MDHS 46. London: HSE, 1985.

14 Dean AD, Dean JA, Burton JH, Dicker RC. Epi Info, Version 5. Atlanta, Georgia: Centres for Disease Control, USA, 1990

15 EGRET. Epidemiological graphics, estimation and testing package analysis module (PECAN), version 0.26.5; EPIX$A C T$, version 0.03. Seattle: Statistics and Epidemiology Research Corporation, 1991.

16 Brooks SM, Baker DB, Gann PH, Jarabek AM, Herzberg $\mathrm{V}$, Gallagher J, et al. Cold air challenge and platinum skin reactivity

\section{Correspondence and editorials}

Occupational and Environmental Medicine welcomes correspondence relating to any of the material appearing in the journal. Results from preliminary or small scale studies may also be published in the correspondence column if this seems appropriate. Letters should be not more than 500 words in length and contain a minimum of references. Tables and figures should be kept to an absolute minimum. Letters are accepted on the understanding that they may be subject to editorial revision and shortening.

The journal also publishes editorials which are normally specially commissioned. The Editor welcomes suggestions regarding suitable topics; those wishing to submit an editorial, however, should do so only after discussion with the Editor. 